\title{
Defining and Explaining Serial Murders in the United States
}

Tae Myung Choo ${ }^{1}$, Young-Shik Choi ${ }^{2}$

${ }^{1}$ Department of Criminal Justice, School of Letters and Arts, University of North Georgia, Oakwood, GA, USA, ${ }^{2}$ National Forensic Service, Wonju, Korea

Received: October 24, 2019

Revised: January 8, 2020

Accepted: February 19, 2020

\section{Correspondence to}

Tae Myung Choo

Department of Criminal Justice, School of Letters and Arts, University of North Georgia, 3820 Mundy Mill

Rd., Oakwood, GA 30566, USA

Tel: +1-615-796-3309

Fax: +1-706-867-2670

E-mail: tae.choo@ung.edu
Serial murder cases in the United States, due to the fact they are rare in numbers and each case has complex nature of the crime, have presented challenges to law enforcement officers and investigators. Academic scholars also have faced obstacles explaining causes of murder within a specific theoretical framework. A steadily rising number of serial murders in recent years prompted this paper to examine the nature of serial murders and their causes in search of answers to questions of 'who they are' and 'why they commit such crimes' Reviewing research studies on serial murder and/or empirical tests of typology of serial murder provided a mixed results and presented a difficulty of classifying serial murders into mutually exclusive categories.

Key Words: Serial murder; Theory of murder; Crime analysis

\section{Introduction}

In recent years, American social media and the public have been fascinated by special homicide cases such as serial killings. Serial murder has been a popular theme on movies, TV shows, and books for decades. This phenomenon has led to perplexing results that people are confusing fiction with fact and misperceptions. Our understanding of repeated murder and its causes are still very limited because there has not been much empirical study on this subject until recent years.

\section{Definition of Serial Murder}

There are difficult views on what define a serial murder and a serial murderer. When defining serial murder, several factors have been considered, which include the number of murder and its interval, the sex of the murderer, the motivational factors behind the murder, and the types of victims. Among them, the most critical three elements are the number of victims, time, and motivation.

The number of victims required for an offender to be classified as a serial murderer varies. According to Holmes and Holmes, a serial killer is an individual who has murdered three or more people over a period of 
more than a month with a "cooling-off" period between murders [1]. The Protection of Children from Sexual Predator Act of 1998 (Title 18, United States Code, Chapter 51, and Section 1111) also defined serial killings as a series of three or more killings. During the Serial Murder Symposium (2005), the Federal Bureau of Investigation (FBI) defined serial murder as "the unlawful killing of two or more victims by the same offender(s), in separate events" [2].

To distinguish serial murder from mass murder, the temporal element is an important factor. While serial murder occurs over time at separate locations, mass murder occurs at one time in on place. Serial murder is also distinguished from spree murder by examining whether the offender has experienced an emotional 'cooling-off' between offenses. If offenders have a cooling-off period, it is a serial murder [3]. The typical motivation for serial murder has been sexual gratification or internal psychological gratification [4]. Holmes and De Burger [5] have identified key elements of serial murder.

- The central element is repetitive homicide.

- Serial murders usually occur between two people: a victim and a perpetrator.

- The relationship between victim and perpetrator is usually that of stranger or slight acquaintance. Serial murder rarely occurs between people who are strongly affiliated.

- Apparent and clear-cut motives are typically lacking in many serial murders. There are, nevertheless, very real motives. These motives govern and structure the serial killer's homicidal behavior.

- Many serial murders are sexual in nature.

\section{Classification of Serial Murders}

\section{Organized/disorganized typology}

Ressler et al. [6] claimed that "the crime scene can be used to aid in identifying the murder." Because "... facets of the criminal's personality are evident in his offense." The most common classification of serial offenses is organized/disorganized typology, which was introduced by the Behavioral Science Unit (BSU) at the FBI Training Academy in Quantico, Virginia, after interviews and the information gathered from the crime scenes, those agents created a system of profiling sexual murderers [7]. The FBI offender profiling is based on a collection of different crime scenes, victim traits, and personal characteristics of the offender that help to build a profile of the murder [8]. In other words, offender profiling involves working backward from a crime scene to develop a description, or profile of the person who committed the crime. According to $\mathrm{FBI}$, there seems a certain interrelation among these three factors, which leads to two categories of typology: organized and disorganized offense. The Crime Classification Manuals by Douglas et al. [9] used this dichotomy to all sexual homicides.

According to their proposition, the organized offender is a person who leads an orderly life that is also reflected in the way he commits his crimes. He exhibits certain characteristics-average to high intelligence, socially competent, and employed in skilled position. In addition, he is apt to plan his crimes, use restraints on his victim, and to bring a weapon with him to commit the murder and to take the weapon away with him from the crime scene. Organized offenders are more likely to use a verbal approach with victims prior to violence. Proponents of disorganized/organized theory suggest that organized offenders are hypothesized to kill after undergoing a precipitating stressful event, such as financial, relationship, or employment problems.

In contrast, a disorganized offender is more likely to be socially incompetent and to have below-average intelligence. The crime scene also reflects a disorder and suggests unplanned act of murder. Evidence, therefore, may be left at the crime scene such as blood, semen, fingerprints, and the murder weapon. He uses minimal restraints and the body is often displayed in open view. In addition, Douglas et al. [9] suggested that the disorganized offender kills opportunistically. A lack of planning will be reflected in the spontaneous style of the offense and the chaotic state of the crime scene. He will live close to the crime scene. The lack of normal, healthy social relationships increases the likelihood of sexual ignorance as well as the potential for sexual perversions or dysfunctions as part of the homicidal acts.

Another typology of serial killers divides killers into 
four categories: visionary, mission, hedonistic, and power/control [5]. Each typology explains the serial killers' motives. Visionary-oriented type responds to delusional voices, seeing visions, and psychosis to kill certain types of people. The crime scene is usually chaotic and contains incriminating evidence, which is the disorganized asocial type. Mission-oriented type murderer targets certain groups of "evil" individuals, such as prostitutes or a particular ethnic group. Mostly these killers are not psychotic and tend to be organized non-social type. Hedonistic-oriented type murderers are the most common form of serial murderers. They can be divided into three sub-categories: lust, thrill, and comfort. All three sub-categories can be either organized or disorganized. Lust killers are motivated by sexual gratification through the use of cannibalism necrophilia, and dismemberment and use violence and torture. Thrill killers are focused on process of killing and attain gratification from the progression of the kill. It is the thrill of killing that motivates them. Comfort killers gain gratification through person gain or profit. Power/control-oriented type wants to have power over the victims. This type of killer is motivated to kill to satisfy their desire for domination and control over their victims. Therefore, they show signs of planning and controlling the crime scene with the modus operandi of an organized non-social typology.

In a revised edition of the book, Holmes and Holmes [1] defined a serial murder as three or more murders and modified the typology model and presented the five types of serial killers: visionary, mission, lust, thrill, and power/control.

Although limited, these studies provide basic information about serial murderers and their victims. The characteristics of serial murderers are usually in their mid-twenties, mostly males, and more likely to be Caucasian than other races. According to the Uniform Crime Report, victims of serial murder are mostly young and middle-aged females, but child victims from a higher percentage in serial murder than victims of homicide. In addition, victims of serial murder are usually strangers to killers.

\section{Criminal investigation analysis}

Another analysis method has also been used by law enforcement. It is called Criminal Investigative Analysis (CIA). CIA is a comprehensive, multidisciplinary method of assessing the facts of a criminal act or series of criminal acts from forensic investigative, scientific, and behavioral perspectives. Using both inductive and deductive reasoning, $\mathrm{CIA}$ incorporates a detailed understanding of case facts, empirical research, clinical psychiatric and psychological principles, and the experience and insight of trained practitioners. The goal of CIA is not to obtain a "profile" of the suspected offender, but to use behavioral science principles to narrow the investigative focus, resulting in a more efficient use of investigative resources.

\section{Theoretical Explanation}

According to $\mathrm{FBI}$ investigation [2], determining the motive of serial murder can be very difficult because serial murderers can have multiple motives for committing a crime and the motives can evolve throughout the series of murders. Nevertheless, during the $\mathrm{FBI}$ symposium in 2005 , several motives were presented and those were anger, criminal enterprise, financial gain, ideology, power/thrill, psychosis, and sexuality. The majority of studies of serial murder has been the biography of an offender or offenders and the causes of their behavior. Academic studies that endeavored to explain the motivation and causality of serial murder apply theories of general aggression and violence to serial murder. Three different academic standpoints, which are mainstream criminological theories-biological, psychological, and sociological theories-have searched for an answer [10].

\section{Biological approaches}

Biological explanations argue that criminal behavior is the outcome of factors internal to the physical body of the individual human being that predisposes that person to criminality. This viewpoint is concerned with our biological processes and the extent to which they have an influence on our behavior. Therefore, offenders 
do not have control over their violent and aggressive behaviors as they are of a nature that acts in such a way. There are several different biological explanations for serial murder. Chromosomal abnormality, the condition of having an extra $Y$ chromosome (XYY), can be linked with criminal behavior. Experts in this field suggest that having an extra $Y$ chromosome can result in an emotionless and unremorseful individual. Childhood trauma or head trauma may also result in aggressive and violent actions. This perspective can be linked to biological trait theories, which explains that impairment of brain function is related to aggression. Biochemical explanations suggest that an imbalance in hormones, blood sugar, or serotonin can have an effect on aggressive and violent tendencies.

\section{Psychological approaches}

Psychology explains criminal and violent behavior in terms of the interactions between our thought processes and our behaviors. As with biology, psychological approach primarily concerned with the individual, but psychology also looks at the individual in terms of their relationships with others (such as attachment theory). Psychological disorders such as depression, stress, and mental health problems can result in violent behavior. The view of the instinct and impulse theory explains that an instinctual or innate quality leads to commit violent and aggressive behavior. On the other hand, the attachment theory examines early life experiences, focusing on the bond between mother and child. It argues that a break in this bond will ultimately direct the child to a life of crime and delinquency. The theory is epitomized by serial murderer Aileen Wuornos. Yet, learning theory focuses on classical conditioning that triggers the killing. The social learning theory concerned about the influence of the media on violent and aggressive behavior and asks the question of to what extent does violent television, books, and movies contribute to a person's violent behavior? Charles $\mathrm{Ng}$ was influenced by John Fowles' book The Collector.

\section{Sociological approaches}

The discipline of sociology attempts to explain human behavior through analysis of the society in which we live, such as social rules and processes that bind and separate people as individuals as well as members of associations, groups, and institutions. Unlike two previous approaches, sociology is interested in our behavior as social beings, as part of a society and how we interact with that society. Three key theories can be applied to serial murder. Anomie/strain theory argues that the strains within our society, and the pressures placed on us to succeed, ultimately force a person to become deviant. Since anomie/strain theory is a structural theory, it argues that the social structure, such as culture and political institutions, shape people and their actions. Richard Kuklinski can be explained with this theory. Labeling theory believes that if a person is labeled deviant, and this label is reinforced, the individual will accept that label, thus affecting the person's self-concept, leading them to identify themselves as deviant and engage in such behavior. Good examples are Aileen Wuornos and Richareed Kuklinski. Control theory suggests that a lack of control is a causal factor for deviant behavior. The control theory states that criminals are those who value immediate gratification and pose a short term view of their life and their goals. Aileen Wuornos is a good case that fits with control theory.

\section{Rational choice approach}

As a modern branch of classical theory, the core premise of rational choice theory argues that crime is a matter of personal choice based on rationality or rational choice. According to the theory, individuals make decisions on whether to commit an offense considering various factors including the effort involved, the potential payoff, the degree of peer support for the action, the risk of apprehension and punishment, and the needs of the individual. Potential offenders make a calculated decision about crime that is mediated by these factors. For example, most serial murderers pick their targets with care and choose victims who are defenseless such as prostitutes, hitchhikers, children, and hospital patients. 


\section{Research on Serial Murder}

Many researches on serial murder have been detailed case studies of serial murderers. The challenge is to find common elements of these murderers as a group. Due to the fact that serial murder is rather a rare crime and the details of the investigation are not available to researchers, group study of serial murders has been scarce. Among several investigations that include more than one serial murderer, the first published study that included direct interviews of offenders was conducted by FBI. This study included 36 sexual murder offenders, 25 of whom were serial offenders [11].

Academic research criticizing the validity of this dichotomous typology has been rising. One of the major criticisms of profiling is its lack of scientific foundation. Other criticism raises the question on reliability and validity of profiling. Questions involve the extent to which criminal behaviors of serial killers are mutually exclusive to each classification (the mutual exclusivity of crime scene behaviors that classified as organized or disorganized); can this be reasonably extended to include the motivations underlying these criminal behaviors? The debate on whether criminal profiling is a science relying on empirical research still continues. Another criticism is concerned that FBI typology cannot account for female serial killer behaviors.

Recently, the study of 61 male serial murders was conducted using Minnesota Multiphasic Personality Inventory-2 (MMPI-2) profiling [12]. MMPI-2 profiling is one of the most frequently administered objective tests for the assessment of personality in forensic assessments, clinical populations, and incarcerated persons. The MMPI-2 is composed of 567 true-false items that can assist in assessments of mental disorders, personality characteristics, and behavioral disorders. The study reported that most sample offenders possess a form of psychopathology. The study sample presents an average MMPI-2 profile code of 4-8-6, which suggests "a severe emotional disorder" [13]. The author also contends that people in such a profile have a tendency to be easily upset, have alienated feelings, be suspicious and overly sensitive, and show a variety of paranoid symptoms. In addition, these persons may rationalize anger with self-justifications, have poor judgment, sexual disturbances, and acute relationship difficulties. Groth-Marnat [14] refers to this type of individual as psychotic.

Canter and Wentink [15] investigated the mutual exclusiveness of the typologies presented by Holmes and Holmes's (1998) [1] using Smallest Space Analysis (SSA-I). This study, using content analysis of crime scene evidence from 100 serial murders, revealed the presence of typical characteristics of 'power/control' killings. However, the result did not support the notion of different types of serial murder based on the motivations and compulsions outlined by Holmes and De Burger's typologies.

More recently, a study explored the validity of organized/disorganized typology and Holmes and De Burger's four-fold typologies (visionary, mission, hedonistic, and power/control) [8]. Adopting content analysis and agglomerative hierarchical cluster analysis, two separate studies were constructed with 50 and 58 crime scene data, respectively. The study attempted to test whether crime scene criteria representative of the many different types of serial murders co-occur in set clusters to support the FBI typology. The result did not provide empirical support for the FBI organized/ disorganized classifications because identifiable clusters formulated by the analysis were not entirely consistent with crime scene criteria stipulated for the $\mathrm{FBI}$ and Holmes and De Burger's typologies. For the Holmes and De Burger's typologies, the study reported two weaknesses: non-mutual exclusivity and overlapping of crime criteria across the typologies.

\section{Discussion}

The organized/disorganized typology formulated by FBI agents has been the most commonly cited classification of serial murder. This dichotomous typology is based on personality characteristics of the offender collected and determined from crime scene information. It is a challenge to classify serial murders or murderers into one of several mutually exclusive categories. One of the problems stems from the data sources. Most typologies utilize a mixture of objective definitions such as crime scene evidence and offender background characteristics, and subjective factors such as psychological motion 
[15]. In addition, these typologies lack empirical testing, which leads to a reliability and validity issue of the model. Studies that conducted empirical tests on common typologies reported similar conclusions. There are some common features and characteristics of serial murders such as power/control nature but assigning these crimes into mutually exclusive categories presented major issues.

Explaining the motives and causes of serial murder also faces a similar dilemma. Various theories from different approaches offer valuable points to explain and evaluate serial murder. Since murder is the results of an interaction of individual, relational, social, cultural, and environmental aspects [16], it is a logical conclusion that the integration of these different angles would provide more powerful and comprehensive insights on serial murder. Collaboration of interdisciplinary work to explore the serial murder would provide in-depth and comprehensive understanding for both murder and murders.

ORCID: Tae Myung Choo: https://orcid.org/0000-00018204-8443; Young-Shik Choi: https://orcid.org/00000001-5564-5277

\section{Conflicts of Interest}

Conflict of interest relevant to this article was not reported.

\section{References}

1. Holmes RM, Holmes ST. Serial murder. 2nd ed. Thousand Oaks, CA: Sage; 1998. p. 4-5.
2. Morton RJ. Serial murder: multi-disciplinary perspectives for investigators. Washington, DC: National Center for the Analysis of Violent Crime; 2005.p. 9.

3. Greswell DM, Hollin CR. Multiple murder: a review. Br J Criminol 1994;34:1-14.

4. DeHart DD, Mahoney JM. The serial murder's motivations: an interdisciplinary review. Omega J Death Dying 1994;29:29-45.

5. Holmes RM, De Burger J. Profiles in terror: the serial murder. Fed Probat 1985;49:29-34.

6. Ressler RK, Burgess AW, Douglas JE, et al. Sexual killers and their victims: identifying patterns through crime scene analysis. J Interpers Violence 1986;1:288-308.

7. Ressler RK, Burgess AW. Crime scene and profile characteristics of organized and disorganized murders. FBI Law Enforc Bull 1985;54:18-25.

8. Taylor S, Lambeth D, Green G, et al. Cluster analysis examination of serial killer profiling categories: a bottom-up approach. J Investig Psychol Offender Profiling 2012;9:30-51.

9. Douglas JE, Burgess AW, Burgess AG, et al. Crime classification manual: a standard system for investigating and classifying violent crime. New York, NY: Macmillan; 1992. p. 212-43.

10. Lee JL, Choi K. Serial murder: an exploration and evaluation of theories and perspectives. Am Int J Contemp Res 2014;4:99-106.

11. Ressler RK, Burgess AW. Men who murdered. FBI Law Enforc Bull 1985;54:2-6.

12. Culhane SE, Hildebrand MM, Walker S, et al. MMPI-2 characteristics of male serial murderers. Appl Psychol Crim Justice 2014;10:21-45.

13. Craig RJ. Interpreting personality tests: a clinical manual for the MMPI-2, MCMI-III, CPI-R, and 16PF. New York: John Wiley \& Sons, Inc.; 1999. p. 87.

14. Groth-Marnat $\mathrm{G}$. The five assessment issues you meet when you to heaven.J Pers Assess 2009;91:303-10.

15. Canter DV, Wentink N. An empirical test of Holmes and Holmes's serial murder typology. Crim Justice Behav 2004;31:489-515.

16. Dogra TD, Leenaars AA, Chadha RK, et al. A psychological profile of a serial killer: a case report. Omega (Westport) 2012;65:299316. 